\title{
Opportunities to Create Active Learning Techniques in the Classroom
}

\author{
Danielle J. Camacho | Jill M. Legare \\ The purpose of this article is to contribute to the growing body of research that focuses on active learning techniques. Active \\ learning techniques require students to consider a given set of information, analyze, process, and prepare to restate what \\ has been learned - all strategies are confirmed to improve higher order thinking skills. Active learning techniques transform \\ complacent and apprehensive learners into active participants in the process. Group assignments and peer review scenarios \\ establish a setting fostering the notion that students who teach one another are essentially learning to teach themselves. Tech- \\ nology in the 21st century allows instructors to incorporate active learning techniques such as web-based scavenger hunts,
} problem-based learning, cooperative learning, group discussion, and peer-reviewed and structured-learning groups into the classroom. This paper will provide a survey of existing literature and will provide examples of methods and techniques that instructors may apply in online and on-ground classrooms.

Chickering and Gamson (1987) remind educators that, "Learning is not a spectator sport. Students do not learn as much just sitting in classes listening to teachers, memorizing prepackaged assignments and spitting out answers" (p. 5). Educators must be flexible and adapt teaching methods and styles to focus on the learner. Wagner (2011) described seven survival skills for our 21st century workforce. Two of the seven survival skills of the 21st century included critical thinking leading to problem solving and accessing and analyzing information (Wagner, 2011). Nenty and Odili (2012) posited education in the 21 st century must be creative, complex, and challenging. In the online classroom the role of the instructor must include teaching students "how to think and communicate effectively" (Wei, Chen, \& Kinshuk, 2012, p. 531). Instructors must motivate students, personalize the learning experience, and strive to provide students with relevant and engaging learning experiences (Meyer, 2013). Educators may incorporate active learning technique (ALT) methods into the classroom and address the concerns researchers have identified with respect to best practices to educate the workforce.

The purpose of this article is to provide a survey of existing literature and to highlight the growing body of research that focuses on ALTs. In this paper the authors introduce potential applications for ALT in the online classroom. The literature review for this paper included topics such as investigating active learning methods, effective teaching techniques, and the value of incorporating ALTs into the classroom to opportunities. Instructors may see the merits of incorporating ALTs such as web-based scavenger hunts, problem-based learning, cooperative learning, group discussion, as well as peer-reviewed and structured-learning groups into the online classroom (Krakowa, 2012).

\section{ACTIVE LEARNING TECHNIQUES}

ALTs encourage students to reflect on the materials, analyze, process, and prepare to discuss - all strategies confirmed to improve higher order thinking skills (Rissanen, 2014). By incorporating active learning methods into the classroom, instructors can create opportunities for learning instead of allowing students to sit passively and learn by absorbing information passed on by the instructor. Kim, Sharma, Land and Furlong (2013) described benefits of ALT to include improved critical thinking skills, 
increased motivation, and enhanced interpersonal communication skills. Zayapragassarazan and $\mathrm{Ku}-$ mar (2012) reported similar benefits of ALT, noting increased student retention and a higher degree of student-focused personal accountability. Application of ALTs offer students opportunities to direct their learning, develop critical thinking skills, and engage in hands-on experience to prepare for realworld job situations. ALTs may empower students and promote synthesis and evaluation that will benefit the learners in all areas of life. ALT may also be used to promote a culture of learning, critical thinking, and student engagement in the classroom (Goldbert \& Ingram, 2011).

Bachelor, Vaughan, and Wall (2012) found that student attitudes and willingness to participate were positively impacted by regularly implementing ALTs in the classroom. Active learning strategies such as group discussion, journal writing, case study, role play, problem-solving, and organized learning groups create opportunities for student participation and engagement (Detlor, Booker, Serenko, \& Julien, 2012). The use of group work and active discussions allow students to both gather information and explore peer perspectives, which further develop application of learning (Levy \& Petrulis, 2012).

Instructor use of active learning strategies may depend on class size, space, objectives, and time available to complete activities. Learning activities may be designed to provide opportunities for students to focus on problem-solving skills which lead to success in learning outcome mastery (Goldberg \& Ingram, 2011; Lee \& Hoffman, 2014). ALT may also incorporate web-based tools (Skiba, 2013). WebEx TM trainings, live training sessions, and group discussion boards are methods to communicate with students to prepare learners to use new technology and tools accessible from the online classroom. The learner-centered approach enables students to both become familiar with resources and to process the relevance of those resources through hands-on exercises. These real-world tools are available to all online learners and may help students generate appropriate learning outcomes (Johnson, Sproles, \& Detmering, 2010).

\section{ACTIVITIES THROUGH WHICH WE LEARN}

Adult learners have needs which are unique, and instructors should consider the needs of the learners in the creation of course and lesson designs. Galbraith and Fouch (2007) emphasized the importance of focusing on adult learning strategies and understanding the role of andragogy in adult learning. Praxis, meaning action with reflection, best illustrates the overall focus on andragogy (Galbraith \& Fouch, 2007). Baker, Sanz Vergel, and Kuntze (2015) found that student engagement in the classroom is malleable. Adult participants in any course will need to understand the small and larger picture and invest time and effort in each lesson. Instructors may positively influence their student success rate as well as student engagement (Baker et al., 2015).

Students learn by talking and listening. A review of literature on active learning revealed a historical study conducted by Knowles (1980), which explained that in spite of creating and describing specific course objectives for a particular class, many of his students still did not understand the specific goals or outcomes. Knowles (1980) found that when students were asked to write the objectives in their own words, they were able to better understand and clarify the curriculum goals. Learning by simulation helps students to develop critical thinking skills and to inform future problem solving (Krakowka, 2012; Bligh \& Bleakley, 2006). Galbraith and Fouch (2007) established that providing a set of learning objectives in the beginning of a lesson would help the adult learners to see the big picture and to know the direction of the session.

Donovan and Loch (2013) illustrated the ways in which implementing educational technology (such as a whiteboard or an audience-response system) in the classroom created an active learning environment which engaged students, promoted frequent feedback, and helped students to develop a deeper understanding of the application of course lessons. Galbraith and Fouch (2007) established that when adults understand the rationale for the lesson, they are more likely to engage in the training and to transfer those lessons to the workplace. Active techniques provide the student the opportunity to organize and reflect; activities which reinforce learning.

One method to foster this learning is accomplished when instructors begin the lecture by asking students to consider a list of pre-designed thought-provoking questions. These questions may 
be asynchronous (as found in many online discussion boards), or synchronous, as seen on a live web seminar. Instructors may also employ this method by stopping a lecture to ask students to reflect on the materials or to be prepared to explain the concepts to the class at the close of the lecture-both methods have proven useful for reinforcing learning (Karmas, 2011).

The initial acquisition of knowledge is followed by comprehension and application for potential scenarios. For example, active learning methods may involve asking students questions such as: "If you experienced a natural disaster and had no Internet access for one week, explain whom would you contact and how might you go about this process?" Student answers would demonstrate the ability to analyze a situation and describe the best course of action. A second scenario may ask students to consider the actions that may result in intentional or unintentional plagiarism.

Students could consider the prompt here: "You have written a paper for a course, but the instructor noted that there was a high percentage match to a Turnitin.com report. Find the academic integrity policy and identify the steps to take to understand the academic integrity policy for our institution. Summarize a list of resources that may be used to ensure your work meets the academic rigor for our institution." Exercises such as these described above allow students to review, analyze, and synthesize information to demonstrate mastery and understanding of the materials.

\section{THE WRITING PROCESS AND GROUP WORK}

The writing process allows students to process and synthesize information. Writing is effective when groups or pairing are not possible or when the class size is too large to ask students to present to the group. Karmas (2011) employed active learning practices in a technical business writing course where students were asked to pre-write papers by creating preview lists. The active learning method allowed students to create lists, then write sentences and repeat until the paper was completed. In the online classroom instructors can create an individual research assignment and ask students to share and discuss findings with a small team. Working in small groups allows students to teach one another how to solve problems and how to apply objectives more globally (Skiba, 2013). Addi- tionally, the use of ALTs in the classroom may result in an improvement in both student engagement and student cooperation (Bachelor et al., 2012). For example, in a master's level online course, Camacho (2014) required students to create a three to five slide PowerPoint presentation focusing on one of 10 assigned Human Resource Law topics. Students submitted the individual assignment for grading, and in the subsequent week students were asked to share their findings with a smaller virtual team via team discussion board. Students reported the benefit of this exercise to include enhanced learning of the materials vis a vie the requirement to teach others about the topic and heightened learning about multiple topics as students were able to learn about the multiple topics researched and shared within the group. Another active learning exercise in the online classroom requires students to interview a business leader and create a PowerPoint describing the key findings. After the individual work is graded students may be asked to share findings with peers in a smaller discussion forum or in a live webinar. In the latter scenario students gain information by interviewing experts in the field and subsequently share this knowledge with peers, passing along insights and best practices.

Several years ago, Legare designed a cooperative learning assignment in the form of a group discussion assignment for an undergraduate United States history course. The design resulted in a debate style exercise in which students chose one of two sides of a discussion concerning whether or not the Civil War was inevitable. The discussion areas designed allowed students to identify all possible options and solutions to this complex issue (Kim et al., 2013). Throughout the duration of the six-week class, students participated in small group discussions, which addressed issues from the bottom-up (working class to the elected officials who held office).

Goals of the exercise included raising real-world issues and allowing students to gain an understanding of the day-to-day experiences that were situated in their proper historical context. Each student was assigned a role; roles included various personas for men, women, children, the wealthy, poor, slaves, slave holders, and office holders. Group discussions may help to bring light to unclear explanations by allowing students who speak the same 'language' to discuss topics in a manner that 
might help to remove confusion about the material (Goldberg \& Ingram, 2011). Students who become comfortable learning from other classmates may be more likely to look to those peers for future guidance, which also helps to develop and maintain networking opportunities (Holland, Major, \& Orvis, 2012). Another example of active learning was cited in a past study from Ohio State where students were asked to complete a reading assignment and then teach other students about the topic. Results from the study indicated that when engaged in this active learning method, students who taught other students, essentially taught themselves (Ohio State, 1988).

\section{PROBLEM-BASED LEARNING}

The problem-based learning method is a teaching technique that fosters the use of critical thinking and problem-solving skills and allows students to take an active role in learning to solve complex problems (Ghosh, 2013; Kwan \& So, 2008). Goldberg and Ingram (2011) reported that students reacted most positively to activities with a focus on research and creativity. Kwan and So (2008) designed a learning experience that required students to investigate a problem, collect and analyze data, and create recommendations for the findings. The results of the study indicated that students who participated in the active learning experiences acquired in-depth knowledge of the topic and developed critical thinking and problem solving skills (Kwan \& So, 2008). Jollands, Jolly, and Molyneaux (2012) found that problem-based learning fostered life-long learning. Researchers determined that students who could solve a problem requiring a focus on research, teamwork, critical analysis, and real-world scenarios would be work ready (Jollands et al., 2012). Similarly, Ghosh (2013) designed a problem-based learning scenario for a master's level economics course. Results from the study indicated students who participated in the problembased learning exercise had a deeper understanding of the subject matter and were adept at applying the theories of international finance to a real-life business venture (Ghosh, 2013).

\section{BRIDGE 'SUCCESS STRATEGIES' COURSES}

Promoting creativity in the classroom helps to produce a more diverse approach to problem solving in other areas (Lee \& Hoffman, 2014); ALTs such as creating a problem-based learning scenario, positively influence student learning. Jansen (2010) concluded that incoming student learning skills and time management skills may positively impact a college student's first-year study behavior and academic achievement. First-year and first-generation online learners face unique challenges with respect to preparing for both the online learning experience and for understanding the resources that are available at the learning institution. First-year online students who are not prepared to take courses may decide to withdraw from the courses instead of accessing relevant resources. Bridge courses help to address this gap by acquainting online learners with institutional resources and technology resources (i.e., writing labs, academic integrity tutoring, and campus services such as career placement). Bridge courses are commonly called, "Success Strategies" or "Introduction to Online Learning." The courses assist students who struggle with their writing skills and focus on identifying the resources that may assist the student throughout the educational process. ALTs built into bridge courses can increase the opportunity for student success (Meyers, 2013).

\section{THE SCAVENGER HUNT}

Twenty years ago, students in an undergraduate environmental studies course were taken on a field trip to Cameron Park, a wooded area in Waco, Texas (J. Legare, personal communication, January 1, 2015). Students were placed into groups and were asked to spend two hours locating specific species of plants and animals. After locating and identifying the flora and fauna, students returned to the classroom. In the classroom, students analyzed the unique contributions of each individual plant and animal, as well as the interconnectedness of these flora and fauna with respect to the larger ecological system in the park. Students engaged in round-table discussions and presented findings to the group. During the presentations students demonstrated mastery of the learning objective measurement, ranging from describing basic knowledge of the systems in place, to analysis and synthesis of the topics. Hands-on active learning processes such as these are still relevant today-although, many times, the scavenger hunt might be a digital one, rather than a walk in the woods.

Field trip assignments no longer require stu- 
dents to leave the classroom. Technology may be implemented to design virtual field trips, which become self-referential and provide simulation of learning that might have been previously prevented based on geography or resources (Bligh \& Bleakley, 2006; Krakowka, 2012). A technical scavenger hunt can be designed to allow students to apply critical thinking to identify the location of materials and to provide an explanation and analysis of the discovery process. Technical scavenger hunts may require students to search solely online or to use technology to locate a physical resource.

Smartphone technology in education and private businesses allows users to access information in an instant. Krakowka's (2012) scavenger hunt utilized Google Earth to create a virtual field trip for students. This exercise required students to use smart phone technology in a scavenger hunt and resulted in students drawing conclusions based on their individual online hunting experience (Krakowa, 2012). Quick Response (QR) codes which provide a digital image linking users with the specific business or item location may also be used in a scavenger hunt assignment. For instance, instructors can create assignments that require students to utilize the code to locate the physical object or item to be studied. Wells (2012) introduced an online scavenger hunt with the purpose of increasing student awareness of the online resources available in the institution. Participating students reported improved knowledge of the resource available and higher levels of engagement in the classroom.

An example of tasks assigned in an online scavenger hunt could include requiring students to locate the online resources for the respective university, and students might locate the student services, online library, writing tutor, and academic policy links. Active learning exercises allow students to self-direct learning. To close an active learning exercise, students may be asked to describe the ways in which the resources identified in a scavenger hunt may be used during the degree program. The outcome from scavenger hunts and resource identification may also be designed to assist graduates to best prepare for their transition into the workforce. For example, a scavenger hunt could be designed to include a search for job prospects, salary information, and resume and cover letter composition tools (Wells, 2012; Segrist \& Nordstrom, 2007).

\section{SELECTION OF ACTIVE LEARNING STRATEGIES: TECHNOLOGY}

The goal of the education process is to teach global lessons; in other words to teach students to 'learn how to learn'. ALT techniques include hands-on web-based tools that are available to online learners and lend to achieving instructor created Bloom's Taxonomic goals (Skiba, 2013). Instructors may incorporate web-based tools, such as Jing or Meebo to best-illustrate a course concept in an online classroom. Jing, an online tool, allows users to record keystrokes and online activities, and it allows visual learners to benefit by watching an instructor complete specific tasks (Bianco $\&$ McCollom, 2009). For instance, if a student does not understand how to use a Drop Box tool within an online course, the instructor could meet with the student and share his screen to walk the student through a demonstration of the tool. A Jing video can capture the audio and visual recordings of meetings in which the instructor may provide instructions and for a student to follow.

Simulation exercises have been used in business, politics, and medical fields. Simulation exercises allow students to work within simulated contexts to complete exercises that develop practical skills and knowledge in the selected field (Keesara, Tessler, Coontz, Chu, \& Stewart, 2013). Course developers can purchase pre-designed simulations to include in the classroom design. CAPSIM, a simulation technology design company, specializes in designing simulations which cater to ALTs. The CAPSIM offerings provide background, context, and ground rules for students who are able to enter into a simulated scenario and make decisions and gain an understanding of the outcomes based on the data set.

Visual learning techniques may also benefit students needing assistance with specific assignments. For example, if an assignment focuses on MLA or APA formatting, the instructor could provide a Jing video accompanied by audio. In many cases, citation errors are minor (placing the punctuation in the wrong place). The use of the Jing videos in the online classroom creates a personalized connection between instructors and students while addressing learning preferences (Karmas, 2011). 


\section{CLOSING REMARKS}

Active learning strategies may bring new perspective and real-world relevance to classroom materials. When designing assignments, instructors may incorporate action words from Bloom's taxonomy - relying on the lists of action words - to help define the actions which will lead to the cognitive processes by which thinkers encounter and work within knowledge (Skiba, 2013). Bloom's (1956) taxonomy model was designed to create an effective objective learning measurement tool which for use in the classroom (Skiba, 2013). Like Bloom's model, ALTs can create a sense of connectedness with the students and the learning materials.

This paper began with a quote from Chickering and Gamson (1987) noting that, "Learning is not a spectator sport" (p. 5). Incorporating active learning strategies into the classroom produces a more effective learning environment and increased student participation and engagement. Senge (1990) may have captured the argument for learning most succinctly observing that students remember only a fraction of what they hear but remember a majority of what they do. Both the online and brickand-mortar instructors have ample opportunities to incorporate ALT into the classroom. Application of ALT offers students a brighter opportunity to develop the abilities and attitudes needed to prepare our learners for success in the 21st century. 


\section{References}

ABachelor, R. L., Vaughan, P. M., \& Wall, C. M. (2012, May 1). Exploring the effects of active learning on retaining essential concepts in secondary and junior high classrooms (Master's research project). Retrieved from: http://library.gcu.edu:2048/ login?url=http://search.ebscohost.com/login.aspx?direct=true $\& \mathrm{db}=$ eric\&AN=ED531546\&site=eds-live\&scope=site. $($ ERIC No. ED531546)

Baker, A., Sanz Vergel, A., \& Kuntze, J. (2015). Student engagement and performance: A weekly diary study on the role of openness. Motivation \& Emotion, 39(1), 49-62. doi:10.1007/ s11031-014-9422-5

Bianco, M., \& McCollom, D. (2009). Jazzed about Jing. [PDF]. Retrieved from http://www.ucdenver.edu/academics/CUOnline/ FacultyResources/additionalResources/Handbook/cuonlinehandbook2011/Documents/chapter9.pdf

Bligh, J. (1995). Problem-based learning in medicine: An introduction. Postgraduate Medical Journal, 71(836), 323-326.

Bligh, J., \& Bleakley, A. (2006). Distributing menus to hungry learners: Can learning by simulation become simulation of learning? Medical Teacher, 28(7), 606-613. doi:10.1080/01421590601042335

Camacho, D. (2014). Incorporating active learning techniques into the classroom. Unpublished Manuscript.

CAPSIM. (2015). About us. Retrieved from http://www.capsim. com/about/

Chickering, A. W., \& Gamson, Z. F. (1987). Applying the seven principles for good practice in undergraduate education. AAHE Bulletin, 39, 3-7.

Detlor, B., Booker, L., Serenko, A., \& Julien, H. (2012). Student perceptions of information literacy instruction: The importance of active learning. Education for Information, 29(2), 147-161.

Donovan, D., \& Loch, B. (2013). Closing the feedback loop: Engaging students in large first-year mathematics test revision sessions using pen-enabled screens. International Journal of Mathematical Education in Science \& Technology, 44(1), 1-13. doi:10.1080/0020739X.2012.678898

Galbraith, D. D., \& Fouch, S. E. (2007). Principles of adult learning: Application to safety training. Professional Safety, 52(9), 35-40.
Ghosh, I. K. (2013). Learning by doing, models to teach undergraduate economics. Journal of Economics \& Economic Education Research, 14(1), 105-119.

Goldberg, N. A., \& Ingram, K. W. (2011). Improving student engagement in a lower-division botany course. Journal of the Scholarship of Teaching and Learning, 11(2), 76-90.

Holland, J. M., Major, D. A., \& Orvis, K. A. (2012). Understanding how peer mentoring and capitalization link STEM students to their majors. Career Development Quarterly, 60(4), 343-354.

Jansen, E., \& Suhre, C. (2010). The effect of secondary school study skills preparation on first-year university achievement. Educational Studies, 36(5), 569-580.

Johnson, A. M., Sproles, C., \& Detmering, R. (2010). Library instruction and information literacy 2009. Reference Services Review, 38(4), 676-768. doi:http://dx.doi. org/10.1108/00907321011090809

Jollands, M., Jolly, L., \& Molyneaux, T. (2012). Project-based learning as a contributing factor to graduates' work readiness. European Journal of Engineering Education, 37(2), 143-154.

Karmas, C. (2011, March). School to work: Using active learning to teach business writing. US-China Education Review, 8(3), 302-316.

Keesara, S., Tessler, R., Coontz, K., Chu, C., \& Stewart, C. (2013). The evolving field of global health education. Global Health Governance, 7(1), 103-114.

Kim, K., Sharma, P., Land, S., \& Furlong, K. (2013). Effects of active learning on enhancing student critical thinking in an undergraduate general science course. Innovative Higher Education, 38(3), 223-235. doi: 10.1007/s10755-012-9236-x

Knowles, M. (1980). Malcom Knowles on...the magic of contract learning. Training \& Development Journal, 34(6), 76.

Krakowka, A. R. (2012). Field trips as valuable learning experiences in geography courses. Journal of Geography, 111(6), 236-244.

Kurtyka, F. (2013). What does your money get you? Active learning as an alternative to consumerism in the composition classroom. Composition Forum, 27, 1-14.

Kwan, T., \& So, M. (2008). Environmental learning using a problem-based approach in the field: A case study of a Hong Kong school. International Research in Geographical \& Environmental Education, 17(2), 93-113. doi:10.2167/irgee230.0 
Lee, S. H., \& Hoffman, K. D. (2014). The "Iron Inventor": Using creative problem solving to spur student creativity. Marketing Education Review, 24(1), 69-74. doi:10.2753/MER10528008240112

Levy, P., \& Petrulis, R. (2012). How do first-year university students experience inquiry and research, and what are the implications for the practice of inquiry-based learning? Studies in Higher Education, 37(1), 85-101.

Meyer, P. (2013). Crafting an approach to online teaching. Journal of Instructional Research Vol. 2, 43-47.

Nenty, H., \& Odili, J. (2012). Skill development gap and applications of Bloom taxonomy-related assessment techniques among teachers in Delta State of Nigeria. International Review of Social Sciences \& Humanities, 2(2), 77-87.

Ohio State Univ., C. E. (1988). Professional teacher education module series: Direct students in instructing other students, module C-4 of category C--instructional execution. Available from ERIC database. (ERIC No. ED149068)

Segrist, D. J., \& Nordstrom, C. R. (2007). Faculty forum: The scavenger hunt-getting to know your psychology department. Teaching of Psychology, 34(2), 100-103.

Senge, P. (1990). The fifth discipline: The art and practice of the learning organization. New York, NY: Doubleday.

Skiba, D. J. (2013). Bloom's digital taxonomy and word clouds. Nursing Education Perspectives, 34(4), 277-280.

Rissanen, A. J. (2014). Active and peer learning in STEM education strategy. Science Education International, 25(1), 1-7.

Wan, Z., Compeau, D., \& Haggerty, N. (2012). The effects of self-regulated learning processes on E-learning outcomes in organizational settings. Journal of Management Information Systems, 29(1), 307-340.

Wagner, T. (2011). Tony Wagner's seven survival skills for 21st century. Retrieved from https://prezi.com/robrm-20llks/tonywagners-seven-survival-skills-for-21st-century/

Wei, C., Chen, N., \& Kinshuk. (2012). A model for social presence in online classrooms. Educational Technology Research \& Development, 60(3), 529-545. doi:10.1007/s11423-012-92349

Wells, V. A. (2012). Hunting for QR codes: Linking students to the music collection. Music Reference Services Quarterly, 15(3), 137-148. doi:10.1080/10588167.2012.700831

Zayapragassarazan, Z. Z., \& Kumar, S. (2012). Active learning methods. NTTC Bulletin, 19(1), 3-5.

\section{Author Biographies}

Dr. Camacho began teaching at GCU in 2010. She serves as an Adjunct Faculty Member at Grand Canyon University, approved to teach business and management courses. Dr. Camacho enjoys coaching and mentoring students in the online classroom. She is a member of the Alpha Phi Omega Fraternity, the Society of Human Resources Management (SHRM) and has served on the peer review board for the Journal of Institutional Research. She resides in Gilbert, Arizona. Dr. Camacho holds several accredited degrees; a Bachelor of Arts (BA) in Psychology from Baylor University; a Master of Business Administration (MBA) from the University of Dallas and a Doctorate of Business Administration (DBA) from Walden University. Her doctoral study, Improving the Environmental Effects of Business Practice Toward Corporate Social Responsibility, provided Dr. Camacho the opportunity to gain professional and academic expertise to facilitate green initiatives within a small company in the construction industry.

Dr. Jill Legare resides in Chicago. Dr. Legare holds several accredited degrees; a Bachelor of Arts (BA) in Journalism from Baylor University; a Master of Arts in History (MA) from Claremont Graduate University, a Masters of Business Administration (MBA) from Keller Graduate School and a Doctorate in Educational Leadership (EDd) from Argosy University. Dr. Legare is an Adjunct faculty member at Colorado State University and Regis College, approved to teach history, business, management, and English courses. Her goal in the online classroom is to promote life-long learning, diversity and ethics in the online classroom. 